\title{
Conflitos sociais e consensos no processo de construção da usina hidrelétrica Foz do Chapecó
}

\section{Social conflicts and consensus in the process of building Hpp Foz of Chapecó}

Myriam Aldana Vargas - Socióloga, doutora em Ciências Humanas e professora do Mestrado em Políticas Sociais e Dinâmicas Regionais da Universidade Comunitária Regional de Chapecó (UNOCHAPECÓ), Chapecó (SC). E-mail: aldana@unochapeco.edu.br

Monica Hass - Doutora em Sociologia Política, Professora Adjunta I e Diretora de Extensão da Universidade Federal da Fronteira Sul (UFFS), Chapecó (SC). E-mail: monica@uffs.edu.br

Geverson Ampolini - Graduando em Direito e bolsista de pesquisa na Universidade Comunitária da Região de Chapecó (UNOCHAPECÓ), Chapecó (SC). E-mail: gever@unochapeco.edu.br

\section{Resumo}

Neste trabalho analisar-se-á o caso da construção da Usina Foz do Chapecó, construída entre os estados do Rio Grande do Sul e Santa Catarina, de modo a compreender a complexidade da dinâmica do empreendimento, bem como os seus efeitos sobre a sociedade regional. Abordarse-á a participação dos diversos atores sociais envolvidos no processo, suas perspectivas e versões dos fatos ocorridos. De um lado, temos o empreendedor e seus aliados, que buscaram efetivar o empreendimento. Do outro, os movimentos sociais regionais, que, na medida do possível, defenderam os seus interesses e os interesses dos atingidos, frente à construção da Usina. Destacase neste artigo o processo de negociação das indenizações aos atingidos, no qual os atores sociais expõem a sua ótica dos fatos, explicitam os diversos conflitos e consensos do processo, e as dificuldades do diálogo em torno de uma efetiva governança.

\section{Palavras-chave}

Governança. Hidrelétricas. Movimentos sociais. Atingidos por barragens.

\begin{abstract}
In this work we will analyze the case of the construction of the HPP Chapecó, built between the states of Rio Grande do Sul and Santa Catarina, in order to understand the complexity of the dynamics of the enterprise, as well as its effects on regional society. We discussed the participation of different actors involved in the process, their perspectives and versions of the facts. On the one hand, we have the undertaking and its allies who wanted finalize the project. On the other hand, there are the regional social movements and affected people that fighted for their interests against the construction of the Plant. Stands out in this article the process of negotiation of compensation to those affected, in which social actors talked about their perspective of the facts, explain the various conflicts and consensus process, and the difficulties of dialogue around effective governance.
\end{abstract}

\section{Keywords}

Governance. Hydropower. Social movements. Affected by dams. 


\section{INTRODUÇÃO}

Neste artigo, acompanhando o caso da instalação da Usina Hidrelétrica Foz de Chapecó, focalizaremos o envolvimento dos diferentes atores sociais, as diversas perspectivas e versões a respeito de como foram os processos de desapropriação dos atingidos, as alternativas encontradas pelo Empreendedor para dar respostas às exigências e as omissões frente às reivindicações do poder público e das populações atingidas, preservando os seus interesses. Além disso, destacaremos a participação dos movimentos sociais, das agências públicas e das organizações privadas, principalmente nas negociações de indenização, evidenciando os conflitos e consensos e as dificuldades do diálogo em torno de uma efetiva governança.

Objetivamos analisar, a partir de informações coletadas, a complexidade da dinâmica da construção desta Usina Hidrelétrica, quando há participação desigual dos diversos atores sociais envolvidos neste processo. Para tanto, foram realizadas entrevistas semiestruturadas com representantes do empreendimento e alguns dos atores que participaram das negociações de indenização. O levantamento documental adensou informações relevantes para essas análises. Há de se mencionar que é um estudo de caso, voltado apenas para a Usina Foz de Chapecó, cobrindo um momento histórico determinado, que, no entanto, permite associar-se aos estudos que analisam, de uma ou outra forma, as disputas em torno da construção das hidrelétricas, que fazem parte da política energética do País.

\section{HISTÓRICO}

A instalação da UHE Foz do Chapecó, empreendimento localizado entre os estados de Santa Catarina e do Rio Grande do Sul, afetado 13 municípios de ambos os estados, faz parte dos projetos hidrelétricos concebidos a partir da década de 1970, pela Eletrosul Centrais Elétricas S.A, que visava o aproveitamento do potencial energético do rio Uruguai, tendo sido o primeiro grande projeto que se formulou para o Brasil, de aproveitamento completo de uma bacia hidrográfica (SANTOS, NACKE, 2001, p. 78).

O interesse pelo rio Uruguai, como fonte para a geração de energia data de 1966, ocasião em que foram efetuados os primeiros estudos visando um inventário hidroenergético da região Sul (FOZ DE CHAPECÓ, 2010). De 1977 a 1979 realizou-se a revisão dos estudos do inventário da Bacia do rio Uruguai pela Eletrosul. Em nenhum desses estudos estava prevista uma usina no local

Novos Cadernos NAEA • v. 16 n. 2 • p. 149-168・dez. 2013 
onde foi instalada a Hidrelétrica Foz do Chapecó (Idem). Entre os anos de 1983 e 1985, por ocasião de estudos de pré-viabilidade para o licenciamento da Hidrelétrica Itapiranga, foi reavaliado o aproveitamento do trecho do rio Uruguai, substituindo o aproveitamento do rio Irai pela Foz do Chapecó. Na bacia do Rio Uruguai, além da UHE da Foz do Chapecó, tem outro importante aproveitamento previsto, que é a UHE Itapiranga, na divisa da Argentina. Segundo a Empresa de Pesquisa em Energia, a usina deve entrar em operação em janeiro de 2018. (Ibid., p. 31). Segundo Baron (2012), com a UHE Foz do Chapecó, já foram construídas nove usinas no rio Uruguai e seus afluentes, transformando os rios e as terras dos pequenos agricultores num grande negócio. São elas: Usina de Itá, Machadinho, Barra Grande, Campos Novos, Manjolinho, Passo Fundo, Quebra-Queixo e São Domingos.

A UHE Foz do Chapecó está instalada na região do Alto Uruguai, entre o Oeste Catarinense e o Planalto Norte Gaúcho. O empreendimento atingiu os seguintes municípios catarinenses: Águas de Chapecó, Caxambu do Sul, Guatambu, Chapecó, Paial e Itá. No Estado do Rio Grande do Sul, os municípios: Alpestre, Rio dos Índios, Nonoai, Faxinalzinho, Erval Grande, Itatiba do Sul e Barra do Rio Azul. A obra afetou, segundo a Foz do Chapecó Energia, 2.503 famílias. O Movimento dos Atingidos pela Barragem (MAB) contabilizou mais 300 famílias não reconhecidas pelos critérios de enquadramento do Empreendedor (LOCATELLI, 2011, p. 26).

A Foz do Chapecó Energia foi a responsável pela construção da UHE Foz do Chapecó. A empresa, atendendo a exigência do Banco Nacional de Desenvolvimento Social (BNDES), modificou a sua estrutura societária no ano de 2007, deixando de ser um Consórcio, tornando-se uma Sociedade com propósito específico, formada pela Companhia Paulista de Força e Luz (CPFL), que detém 51\% das ações, Furnas Centrais Elétricas, com 40\% das ações e a Companhia Estadual de Geração e Transmissão de Energia Elétrica (CEEEGT), com 9\% das ações. A previsão orçamentária para a obra era de $\mathrm{R} \$ 814$ milhões, mas foram gastos no total $\mathrm{R} \$ 2,2$ bilhões, sendo que 1,6 bilhões foram financiados pelo o BNDES (BARON, 2012).

Um elemento central a ser considerado neste processo é que a decisão da instalação da Usina faz parte da política energética do governo, fato que impede qualquer possibilidade da comunidade local e regional alterar esta decisão, pois o que está em primeiro plano é a necessidade nacional e internacional da produção de energia ${ }^{1}$. Estas decisões verticais permitem que o empreendedor responsável

A respeito ver Vainer e Araújo (1992); Bermann (2007); Zhouri e Oliveira (2007) e Locatelli, (2011). 
pela construção se sinta distante de uma gestão participativa, assumindose, portanto, como um mero construtor de uma obra já definida, conforme afirmação do Diretor Superintendente do Consórcio Foz do Chapecó Energia:

Quem define onde será construída uma Usina, a sua capacidade, não é o Empreendedor. É uma questão de governo, ele tem a sua empresa de planejamento de expansão do setor elétrico, ela define onde serão construídas as Usinas. Isto faz do que se chama inventário, ela vai aos rios e diz que aqui pode ser construída a Usina, aqui não. Para que uma Usina seja construída, ela precisa passar por esse processo de licenciamento; é uma questão de governo. Não é o interesse do Empreendedor em construir uma Usina; o Empreendedor entra no processo como decisão de uma decisão já tomada. Aqui vai ser construída uma Usina, quem se habilita. Esses conflitos entre gente que quer manter o rio no seu curso normal e a necessidade de geração de energia, não é um conflito empreendedorsociedade; é um conflito de diversos segmentos da sociedade. O governo e outros setores que precisam da energia elétrica, contra aqueles grupos que gostariam que a energia fosse produzida de outras formas. Esse é um conflito que sempre existiu e vai continuar existindo, não apenas no Brasil, mas em vários lugares do mundo. $\mathrm{O}$ Empreendedor muito pouco interfere nesse processo; o Empreendedor é que uma vez decidida a construção da Usina e as condicionantes que têm de ser atendidas, é que ele busque negociar uma forma de atender esses negociantes (Enio Emilio Schneider, Diretor Superintendente do Consórcio Foz do Chapecó).

A construção da UHE Foz do Chapecó integra o primeiro Programa de Aceleração do Crescimento (PAC I) do governo de Luís Inácio Lula da Silva, que está vinculado ao aprofundamento do modelo de integração competitiva da economia brasileira no cenário internacional (VIGNATTI, 2013). Atualmente existe um conjunto de instituições responsáveis pela elaboração e implementação da política energética brasileira, sob o comando do Ministério de Minas e Energia. Os documentos que orientam as ações da política energética, do ponto de vista estratégico, são o Plano Decenal de expansão da Energia 2011-2020 (MME/ EPE, 2011) e o Plano Nacional de Energia 2030 (MME/EPE), que indicam a exploração do potencial hidroenergético do país, dobrando a capacidade atual de energia hidrelétrica no Brasil, até o ano 2030. Entretanto, como essas grandes obras não nascem dos anseios da população e causam enormes impactos econômicos, sociais e ambientais, principalmente às populações atingidas, os conflitos acompanham todo o processo de construção das hidrelétricas, como será visto ao longo deste texto. 


\section{AS LICENÇAS AMBIENTAIS E AS AUDIÊNCIAS PÚBLICAS}

De acordo com a resolução do Conselho Nacional do Meio Ambiente (CONAMA) $\mathrm{n}^{\circ}$ 006/87, são três as licenças ambientais necessárias para a construção de empreendimentos de grande porte, especialmente de energia elétrica: a Licença Prévia, fornecida na fase preliminar do planejamento da obra, que é uma maneira de controle e planejamento ambiental, em que se averiguam a viabilidade técnica e ambiental do empreendimento (MARÇAL, 2005); a Licença de Instalação, que autoriza a instalação do empreendimento, de acordo com as especificações do projeto; e a Licença de Operação, que autoriza o início das atividades da hidrelétrica.

Em dezembro de 2002, ao final do governo de Fernando Henrique Cardoso, o Instituto Brasileiro do Meio Ambiente e dos Recursos Naturais Renováveis (IBAMA) concedeu a licença prévia para o início da construção da obra, após análise e aprovação do Estudo e Relatório de Impacto Ambiental do empreendedor (FOZ DO CHAPECÓ, 2010). A licença de instalação foi liberada em 2004 e renovada em 2006.

A concessão para a construção do empreendimento foi expedida pela Agência Nacional de Energia Elétrica (ANEEL) em 2007, com validade de 35 anos (FOZ DO CHAPECÓ, 2010). A licença de operação da hidrelétrica foi concedida pelo IBAMA em agosto de 2010, após vários recursos judiciais, com validade de quatro anos (FOZ DO CHAPECÓ, 2010; HASS; ALDANA; AMPOLINI, 2010).

Além disso, em 1986 o Conselho Nacional do Meio Ambiente (CONAMA), através da Resolução $n^{\circ}$ 01/86, regulamentou a obrigatoriedade da realização de Estudos de Impacto Ambiental (RIMA), para fins de licenciamento ambiental.

Segundo a Resolução do CONAMA nº 009/87, a audiência pública objetiva expor aos interessados o projeto em análise e o Relatório de Impacto Ambiental (RIMA), esclarecendo dúvidas e recolhendo críticas e sugestões sobre o empreendimento e as áreas a serem atingidas. A audiência pública não tem poder deliberativo, e será promovida pelo órgão ambiental sempre que se julgar necessário ou quando for solicitada por entidade civil, pelo Ministério Público ou por 50 ou mais cidadãos (MACHADO, 2000).

As primeiras audiências públicas que colocaram em debate o projeto de empreendimento da Usina Hidrelétrica Foz do Chapecó e o Relatório de Impacto Ambiental ocorreram no dia 11 e 12 de abril de 2002, nos municípios de Chapecó (SC) e de Alpestre (RS). Diferentes instituições, entidades e movimentos organizados da sociedade civil presentes nessas audições tiveram a oportunidade 
de se pronunciar, frente ao projeto apresentado. Todas as informações repassadas pelo empreendedor, bem como as questões levantadas pelos participantes da audiência, fazem parte do processo de licenciamento ambiental prévio expedido pelo IBAMA.

Em 31 de maio de 2010, quando a obra já estava praticamente concluída, aconteceu uma nova audiência pública em Chapecó, promovida pelo Ministério Público Federal, com a participação do IBAMA e do Ministério de Minas e Energia. O Consórcio Foz de Chapecó também foi convidado, mas não compareceu ao evento. O objetivo era verificar se os problemas que constam no dossiê encaminhado pelo MAB ao Ministério das Minas e Energia e à Secretaria Especial de Direitos Humanos da Presidência da República ${ }^{2}$, bem como as demais denúncias feitas pelo Consórcio Iberê, órgão que presta assessoria sobre os impactos da construção da hidrelétrica Foz do Chapecó aos municípios atingidos, estão, de fato, acontecendo na região.

Outro ponto importante abordado no evento foi o questionamento da Associação Mista dos Municípios Atingidos pela Barragem Foz do Chapecó (AMISTA) sobre a validade do documento protocolado junto ao IBAMA após a audiência pública ocorrida em Chapecó, no dia 12 de abril de 2002, como parte do processo de licenciamento ambiental, uma vez que as reivindicações da associação junto ao empreendedor, na mesma audição, não foram cumpridas. O Movimento dos Atingidos por Barragens (MAB), por sua vez, também afirmou que as suas reivindicações não foram contempladas nos licenciamentos ambientais expedidos. Enquanto estas pendências não fossem resolvidas pelo empreendedor, entidades, gestores públicos, MAB, Ministério Público Federal, Consórcio Iberê, AMISTA e outros, solicitavam que não fosse liberada a licença de operação da Usina Hidrelétrica Foz de Chapecó.

Essas audiências públicas de 2002 simbolizam uma limitada gestão participativa, deflagram um processo pouco efetivo de divulgação, e muito menos efetivo no que tange à mobilização e educação para a participação política. Este grande empreendimento foi apresentado a um público reduzido, com poucos representantes das diversas organizações da sociedade civil e com insignificante

\footnotetext{
O Movimento dos Atingidos por Barragens encaminhou à Secretaria Especial de Direitos Humanos da Presidência da República um relatório contendo inúmeros vícios do processo prévio de licença ambiental e do processo de indenização dos atingidos: averiguaram-se problemas no EIA-RIMA, com o subdimensionamento das famílias atingidas nos estudos, o desrespeito ao direito de opção pela modalidade de indenização; problemas relativos a pessoas que vivem próximo da construção da obra, casos negados, despejos de pessoas, falta de indenização para algumas famílias, situação de pescadores atingidos não indenizados, questionamento da data-base do cadastro socioeconômico, retrocesso nas condições de vida da população atingida e sobre a criminalização do movimento social (BRASIL. Resolução n' 26/2006, p. 25-49).
}

Novos Cadernos NAEA •v. 16 n. 2 • p. 149-168 • dez. 2013 
participação por parte dos representantes da administração pública em duas audiências, considerando que este projeto afetará o desenvolvimento regional de 13 municípios (HASS; ALDANA; AMPOLINI, 2010).

De acordo com Agra Filho (2010, p. 355), a audiência pública "é fundamentalmente um momento de consulta e de identificação de conflitos". Ainda segundo o autor:

[...] a fragilidade do debate e as próprias condições em que as informações são fornecidas dificultam um questionamento mais elaborado sobre os objetivos do projeto e as potencialidades que ele representa e, sobretudo, sobre os conflitos de uso que pode trazer. Ao contrário, em geral, o projeto torna-se um mero documento publicitário do empreendedor, ainda que os resultados das audiências sobre a sua execução tenham sido considerados satisfatórios pelos órgãos ambientais, conforme levantamento do Ministério do Meio Ambiente (AGRA FILHO, 2010, p. 357).

As audiências públicas, como mecanismo de participação pública, têm sido um espaço para gestores públicos e sociedade civil demonstrarem a insatisfação em relação à minimização dos problemas ambientais identificados pelo empreendedor do RIMA. No entanto, as críticas e os questionamentos apresentados nas audições geralmente não são considerados como condicionantes para a licença de instalação da hidrelétrica, mesmo porque, na sua maioria, quando apresentam pontos de vista conflituosos ao projeto, não são registrados nas atas das audiências públicas.

\section{AS NEGOCIAÇÕES DA INDENIZAÇÃO DOS ATINGIDOS: MÉTODOS, ESTRATÉGIAS, ATORES}

Verificar-se-á, neste item, como se dá a governança, ou seja, a interação local entre os atores sociais, o governo e a empresa responsável pela construção do empreendimento, com o objetivo de verificar a existência ou não do estabelecimento de um diálogo entre os diferentes atores sociais envolvidos no processo da construção da hidrelétrica, visando um consenso, principalmente em relação às negociações envolvendo a indenização dos atingidos.

Para que se proceda à construção de uma usina, é essencial que as propriedades atingidas sejam indenizadas, como dispõe a Constituição Federal de 1988. Entretanto, o próprio conceito de atingido tem diferentes pontos de vista, disputados entre o empreendedor e os movimentos dos atingidos, e discutidos por autores que trabalham com o tema. Para Vainer (2008): 
[...] na concepção territorial-patrimonialista "o território atingido é concebido como sendo a área a ser inundada e a população atingida é constituída pelos proprietários fundiários da área a ser inundada. Nestas circunstâncias, a ação do empreendedor resume-se a avaliar e negociar as desapropriações, do que se desincumbe seu departamento de patrimônio imobiliário ou (similar)" (VAINER, 2008, p. 43).

Nesta perspectiva, a população é um obstáculo a ser removido, objetivando a viabilização do empreendimento.

Uma outra concepção de atingido, segundo Vainer (2008, p. 43), continua predominando na prática, que é a "concepção híbrida"; e que, "mesmo quando reconhece os não proprietários, isto é, os ocupantes, posseiros, meeiros, etc. esta perspectiva tende a circunscrever especialmente os efeitos do empreendimento, estritamente à área a ser inundada" e considera que "os municípios a serem compensados são aqueles que têm parte de seus territórios inundados".

O Consórcio Foz do Chapecó, no documento de 2010, ressalta que existem critérios "precisos e justos" para que os atingidos sejam indenizados. Os proprietários e posseiros de "boa fé" são indenizados ou, se optarem, recebem a modalidade de indenização Carta de Crédito ou, ainda, recebem uma nova área, num Reassentamento Rural Coletivo. Afirma, também, que a Carta de Crédito e o Reassentamento são concedidos a não proprietários (arrendatários, meeiros e parceiros rurais). Como menciona o próprio empreendedor, esse processo ocorre mediante reuniões com os atingidos em suas comunidades locais, através de "transparência e diálogo", preservando o "bem-estar" dos moradores (FOZ DO CHAPECÓ, 2010).

Neste sentido, o Diretor Superintendente da Foz do Chapecó Energia, Enio Schneider, destaca, em entrevista, que não existe a possibilidade de que algum proprietário dentro da área alagada ou da área de preservação não tenha sido indenizado. Declara ser uma questão legal, independente do processo de negociação. Referiu, ainda, que houve cuidado na definição dos critérios de negociação, e que não existe a menor possibilidade de que algum atingido não tenha sido indenizado. E acrescenta:

[...] Agora, existem aquelas pessoas que dizem: eu não sou proprietário, mas eu sempre vivi e trabalhei nessa propriedade. Dessas pessoas foi feito um cadastro antes do leilão do empreendimento, e foi atualizado na emissão da licença da instalação. Quem consta nesse cadastro, ali é levantado tudo, não apenas quem é proprietário, quem trabalha na área, seja como empregado ou arrendatário; essas pessoas são analisadas caso a caso, e quem de fato comprova de que na época na licença - porque depois da licença, muita gente chega atraída por promessa, vamos lá que você vai ser indenizado, vai receber uma carta de crédito -, quem de fato comprova

Novos Cadernos NAEA • v. 16 n. 2 • p. 149-168 • dez. 2013 
que à época da concessão da licença dependia daquela terra é indenizado (Ênio Emilio Schneider, diretor superintendente do Consórcio).

Ao longo da entrevista com a direção do Consórcio, constatou-se um diálogo alinhado com o depoimento acima: "a empresa analisou cada caso, tudo o que foi solicitado pelos representantes dos atingidos foi concedido, atendemos todos os grupos tais como o MAB, a AMISTA e os Comitês de Negociação, enfim, nenhum entrave no processo de negociação foi apontado". Vejamos, então, o posicionamento, fatos e versões destes três atores mencionados pelo empreendedor, e que também participaram desse processo.

O MAB é um movimento social que surgiu nos anos 1980, quando a Eletrosul anunciou os 25 projetos que seriam construídos no Rio Uruguai, como afirma a liderança do MAB entrevistada:

[...] quando a Eletrosul dá a notícia para a região, de que seriam construídos 25 projetos no Rio Uruguai, surge na época, o MAB, pois os camponeses e agricultores começaram a se preocupar, e principalmente com os sindicatos combativos da época e a Igreja Católica, a Evangélica, a CNBB e a faculdade de Erechim, começaram a fazer a organização dos atingidos e, principalmente, quem teve um papel fundamental foi o Bispo Dom José Gomes. A partir desse processo, eles começaram a alertar os agricultores sobre o perigo que rondava a Bacia do Uruguai, que à época se acreditava que algo em torno de quarenta e cinco mil famílias de agricultores teria de sair das suas terras, para a construção dos Grandes Lagos (Pedro Melchiors, liderança do MAB).

Em 1979, foi criada, no município catarinense de Concórdia, a Comissão Regional dos Atingidos por Barragens (CRAB), precursora do MAB. Contudo, o movimento não logrou êxito instantaneamente, já que faltava a este o apoio da população regional. Porém, a partir da realização da Romaria da Terra em Itá, em 1985, a história se inverteu: reuniram-se mais de cinco mil pessoas no município, o que fez com que as sociedades locais e o Estado considerassem a CRAB/ MAB como legítimos representantes das populações atingidas (POLI, 1999, p. 145-158).

No caso dos movimentos sociais dos atingidos, é imprescindível compreender que estes movimentos se constituem essencialmente como respostas de sociedades tradicionais à lógica seletiva do capitalismo, em contraposição aos conceitos de valorização da família, posse da terra e solidariedade de sociedades regionais (ROCHA, 2010, p. 11-12). Neste sentido, Tourraine (apud GOHN, 2005, p. 109-114) afirma que um movimento social pode ser definido como uma união de conflito contra um adversário social organizado, e do marco comum 
de embate entre adversários, em referência a um mecanismo cultural, sem o qual inexistiria conflito.

Com relação às indenizações e as estratégias de negociação utilizadas pela UHE Foz de Chapecó, mesmo que seu representante tenha declarado que "todos foram indenizados", o interessante é observar, porém, se todos os atingidos foram de fato indenizados, como foram indenizados e como foram convencidos a ser indenizados. De acordo com o MAB, 10\% das propriedades "indenizadas" estão em disputa na Justiça. Ou seja, 10\% dos atingidos não concordaram com o valor pago na indenização.

Além disso, o MAB denunciou inúmeras práticas que a empresa utilizou para fazer com que grande parte destas áreas de terra fossem adquiridas de modo "amigável", sem a necessidade de utilização da via judicial.

[...] O Consórcio vai fazendo o jogo psicológico. Se o atingido não quer, o Consórcio o deixa amadurecer, vai cansando ele. Então começa a questão, tu és do MAB, então fica para trás. Seria então o momento de fazer uma luta, pois a negociação não avançava. Tinha uma dificuldade de mobilizar gente, por causa desses fatores. Pois, a nova prática que está sendo usada por eles, está sendo espalhada para outras regiões do Brasil, o MAB já está vendo isso. Eles contratam gente da região para ajudar a fazer o trabalho, e às vezes gente "de esquerda" que é próximo da luta e da organização, que começa a ganhar dinheiro (Pedro Melchiors, liderança do MAB).

Por conta dessas estratégias utilizadas, o movimento social acabou sendo despotencializado, devido aos pequenos conflitos surgidos entre os próprios atingidos. De acordo com o entrevistado Pedro Melchiors, a força de um movimento social está na sua base. E para esse ponto "forte" do movimento, convergiram "interesses divergentes", no sentido de acabar com o movimento social pela base, na velha regra do "dividir para conquistar".

Ressalta-se o papel de outro ator dentro desse processo: a AMISTA, constituída segundo informações do MAB, com o claro objetivo de ser um grupo de interesse a favor da construção da Barragem. A Associação Mista dos Municípios Atingidos pela Barragem Foz do Chapecó (AMISTA) surgiu da união de famílias atingidas pelas usinas das cidades de Águas de Chapecó (SC) e Alpestre (RS), com o objetivo de defender os seus interesses perante a Foz do Chapecó Energia (STRADA; TUMELERO, 2005, p. 53).

O processo de organização dessas famílias partiu da iniciativa do nosso entrevistado, o ex-prefeito de Águas de Chapecó e liderança da AMISTA, Adilson Zeni. Segundo ele, foi em meados de 1998 que se buscou fazer um trabalho mais focado na construção da hidrelétrica, período em que ele estava na condição de 
prefeito do município. Adilson relata que a formação da AMISTA aconteceu pelo fato de possuir amizade com um engenheiro civil que trabalhava para a Eletrosul, e de um dos acionistas da ETS (empresa que fazia o estudo socioeconômico da região), que o incentivaram a organizar os atingidos de modo diferente do que o MAB fazia. Pois, segundo ele:

[...] a orientação desses dois amigos foi a seguinte: olha, o MAB é um movimento que tem sua validade, mas atua de forma bastante radical, eu acho que isso não leva a nada. Eu sugiro que você organize a população atingida de uma forma madura, equilibrada e que estabeleça uma relação de conhecimento sobre o que é a obra e das consequências. Especialmente com relação às indenizações, as cartas de crédito, as formas de indenização e de pagamento. (Adilson Zeni, Liderança da AMISTA).

Refere, ainda, que um dos principais objetivos da AMISTA foi de "organizar, buscar uma negociação, receber informações que algumas vezes chegavam distorcidas [...] vamos tornar claro isso aqui para ver exatamente o que vai acontecer" (Adilson Zeni, liderança da AMISTA). Ou seja, a AMISTA se constituía num grupo de atingidos que objetivava defender os direitos relativos à indenização, e que também se manifestava favoravelmente à construção da Usina, o que fica muito claro na fala do nosso entrevistado.

Foi na comunidade linha de Saltinho do Uruguai, uma comunidade que foi atingida pela construção da hidrelétrica [...] aqui em Águas de Chapecó, que nós realizamos a primeira reunião com os atingidos no final de 1998, início de 1999. [...] E nós lá então acompanhados do Pedro Paulo Bortolini Jr., ele é um dos acionistas da ETS, a empresa que fez o levantamento sócioeconômico da região atingida pela Foz do Chapecó. [...] Na oportunidade, em cima dessa orientação, em cima da orientação que eu recebi desse meu amigo, do Paulo Boamar, eu propus de que nós tivéssemos um canal de contato com uma diretoria que viesse a ser formada. E naquela reunião, deu origem, por indicação das pessoas, de nós termos um grupo de cinco pessoas, com quem seria mantido o contato permanentemente sobre a evolução do andamento das questões relacionadas à Foz do Chapecó. Essas cinco pessoas eram da comunidade, atingidos, principalmente agricultores (Adilson Zeni, Liderança da AMISTA).

Foi depois deste primeiro, que começou a haver uma periodicidade de encontros, a fim de se obter informações relativas à obra, e assim se constituiu uma diretoria de atingidos no município de Águas de Chapecó. Depois de diversos encontros entre o Prefeito e essas pessoas, no ano de 2000 estes visitaram a Hidrelétrica de Machadinho, a fim de averiguar qual era a situação dos atingidos daquele empreendimento, sendo que foram feitas até mesmo filmagens das visitações ao empreendimento. De um modo geral, os que fizeram as visitações 
entenderam que a situação dos atingidos naquele empreendimento era positiva. Os dados colhidos em Machadinho foram trazidos e apresentados numa reunião na Linha Saltinho do Uruguai, e os mesmos vídeos foram apresentados em Lajeado Bonito e Linha Pegoraro, e as reações dos atingidos foram sempre "positivas". Posteriormente a isso, o entrevistado relatou que:

Num segundo momento, quando eu não estava na prefeitura, eu estava como Secretário de Desenvolvimento Regional de Palmitos, nós fomos a Campos Novos, em visitação a obras, em contato com as pessoas que haviam sido indenizadas [...]. E as pessoas que foram constataram que aqueles benefícios foram positivos. Em decorrência disso, a gente percebeu que o MAB, que estava assim bastante aguerrido, também não teve mais muita credibilidade (Adilson Zeni, Liderança da AMISTA).

Em decorrência do trabalho desempenhado, o entrevistado comentou que os atingidos de Alpestre (organizados em outra diretoria) convidaram a diretoria de atingidos de Águas de Chapecó para mostrar o seu trabalho. Nesse encontro, os atingidos de Alpestre sugeriram que as duas diretorias se reunissem, de modo a fazer um trabalho coordenado. Sugeriu-se que fosse formada uma Comissão "Mista" de atingidos, de onde proveio o nome "AMISTA". O prefeito ressalta que uma das principais conquistas da AMISTA foi o valor conseguido pelas terras, pois se fez uma avaliação num raio de 200 quilômetros, onde se buscou valores em locais de terra mecanizada como padrão, com valores maiores do que os comercializados em nível local. Os valores das benfeitorias, bem como de áreas de pastagem apresentados pelo Empreendedor, também foram contestados pela AMISTA.

O MAB considera que a criação da AMISTA teve como propósito o monopólio da representação dos atingidos, e, sobretudo, o de desqualificar o movimento social, situando-o como entidade prejudicial aos processos de negociação. A liderança do MAB destacou que o movimento sempre buscou envolver toda a sociedade civil nas discussões sobre as indenizações, por entender que "a força de um movimento está no debate com a sociedade". A AMISTA, por sua vez, segundo Pedro Melchior, considerou que o procedimento deveria contar diretamente com as prefeituras e com a empresa, para juntamente resolver qualquer problema de forma individual com cada atingido(a), desarticulando qualquer possibilidade de organização popular.

[...] Então eles criaram uma AMISTA, e nesse processo ela desencadeou muitas disputas no município onde é que o MAB fazia as lideranças nossa da coordenação, fazia disputa com o vizinho dele na comunidade. Começou a criar atrito entre os povos atingidos, então em vez de haver uma forma de resistência, de fazer a discussão do que vai ser o impacto,

Novos Cadernos NAEA • v. 16 n. $2 \cdot$ p. 149-168 • dez. 2013 
do que vão querer, começou a disputa de atingido contra atingido. Então aí eles criaram a AMISTA. Essa AMISTA então foi fazendo o debate e foi dando o suporte para o consórcio foz do Chapecó. Então começou a articular encontros, a fazer debates, fazer opinião pública, mídia. (Pedro Melchiors, liderança do MAB residente em São Carlos).

O próximo ator social desse processo são os Comitês de Negociação, organizados por iniciativa da AMISTA, e que acabaram se tornando instrumentos de promoção dos interesses do empreendedor. Vale ressaltar que a Associação Mista dos Atingidos pela Barragem Foz do Chapecó foi quem organizou a criação e a coordenação desses Comitês em cada município (Adilson Zeni, Liderança da AMISTA). Os Comitês Municipais de Negociação surgiram inicialmente por ação conjunta dos prefeitos da região atingida, via entidade AMISTA, e seu objetivo principal era o de intermediar as negociações entre os atingidos e a Foz do Chapecó. O Secretário Municipal para Assuntos da Barragem de Caxambu do Sul, Lenoir Rolim de Moura, na sua entrevista declarou explicitamente que "os Comitês foram criados nos municípios: eu não tenho medo de dizer que a Foz manipulou o seu interesse".

A AMISTA era formada por um representante de cada Comitê Municipal de Negociação. Como relata a liderança da AMISTA de Águas de Chapecó:

[...] Os comitês eram municipais e a AMISTA era um guarda-chuva, onde abrigava os comitês municipais. [...] A AMISTA era uma coordenação geral dos comitês. [...] Quem coordenava os comitês era a AMISTA, pelo seu presidente. Nós tivemos diversos presidentes. [...] E a AMISTA era quem dialogava com o empreendedor. [...] Mas um comitê poderia dialogar independente com a Foz, sim [...] (Adilson Zeni, liderança da AMISTA).

A atuação dos Comitês Municipais de Negociação se deu basicamente na discussão de assuntos relativos à indenização dos atingidos. Não foram tratados outros assuntos relevantes nestes comitês, como questões relativas ao meio ambiente, a compensações aos municípios atingidos. Talvez por esse fato, que a instituição destes Comitês tenha sido tão questionada pelos entrevistados, já que eles aparentemente atuaram junto aos interesses do empreendedor e não dos atingidos.

[...] Os comitês eram braços da AMISTA. [...] Que houve diversas reuniões com os Comitês locais, mas depois destas reuniões individuais, também novamente a AMISTA e os Comitês nesse colegiado de comitês buscaram tratativas com a Foz do Chapecó. Onde foram estabelecidos principalmente critérios para a avaliação de preço de terra. Onde foi feito uma consulta em cada município e cada um teve a oportunidade de buscar essas informações num raio de até duzentos quilômetros de sua sede [...]. 
Depois se chegou a um entendimento de uma média geral de preços de terra (Adilson Zeni, liderança da AMISTA).

A forma de composição desses Comitês variava de município para município. Em Águas de Chapecó, constituiu-se unicamente por atingidos, enquanto em Caxambú do Sul, participou uma grande variedade de pessoas, como atingidos, membros do comércio, representantes da prefeitura, de Igrejas etc. Estas composições também foram questionadas pelo MAB, pois, segundo eles, apenas os atingidos é que deveriam fazer parte dos Comitês e não agentes estranhos ao processo.

Por exemplo, se criava um Comitê [...], o Comitê iria discutir as propostas que a empresa iria apresentar [...]. Vocês vão ser mais um no processo, lá vai ter um da prefeitura, um do comércio, um do sindicato. [...] Os que entraram no Comitê eram do pessoal da AMISTA, que já tinha conflito com o pessoal do MAB. E aí começou a disputa, pois seria um comitê de treze pessoas que iria definir o acordo para os atingidos, e nós dissemos que o MAB trabalha de forma democrática, quem deve definir o futuro da indenização deve ser o próprio atingido [...]. Quem definiu as regras dos atingidos não eram os atingidos, eram as pessoas da cidade (Pedro Melchiors, liderança do MAB).

Outro ponto questionado foi o fato de que as pessoas que participaram desses Comitês não possuíam experiência em indenizações, tal qual o MAB possuía, já que o Movimento de Atingidos é o que mais acumulou experiência na fixação de critérios em acordos desse tipo. Contudo, o Movimento preferiu se ausentar dos Comitês, pois os considerava pouco representativos, uma vez que estavam sendo constituídos por pessoas com diferentes interesses, muitos deles distantes dos interesses dos próprios atingidos.

O representante do $\mathrm{MAB}$ afirmou ainda que os Comitês Municipais recebiam ajuda de custo da Foz de Chapecó Energia:

[...] mas o que o pessoal diz. É que o consórcio começou a pagar para as pessoas dos comitês, diárias, alimentação, corrida, hospedagem e tudo. E a pagar dois mil reais por mês para cada comitê em forma de aluguel. E vocês perguntam por que o MAB não é mais o principal ator dentro desse processo! Pois as empresas começaram a disputar a base. Os comitês implementaram a proposta da empresa, pois eles não tinham experiência em indenização, regras, critério e tal. Pois as pessoas, assim, acabavam assinando o que a empresa colocava, e por isso deu muita contradição. Então houve uma redução nos direitos que nós conseguimos em outras barragens (Pedro Melchiors, liderança do MAB). 
Das reuniões da Foz do Chapecó com o Comitê, depois de finalizadas as negociações, surgiu o documento registrado em cartório, intitulado "Acordo de Remanejamento da UHE Foz do Chapecó", que fixou os principais critérios a serem seguidos no processo de indenização e realocação dessas pessoas. Quando alguém discordava da sua indenização, formava-se uma Comissão Paritária para analisar o caso. Participavam da Comissão Paritária, de um lado, a Foz do Chapecó, representada por sua assessoria jurídica e a assistente social e, de outro, o MAB e o atingido. Segundo o representante do MAB, Pedro Melchiors, ocorreu uma inversão de valores nesse processo, pois ao invés do atingido fazer valer os seus direitos, acabou saindo com "uma migalha de indenização".

As reuniões paritárias entre os representantes da empresa e os atingidos foram alvo de críticas por parte do MAB, visto que os atingidos são, em regra, pessoas essencialmente humildes, com um mínimo grau de instrução, e não foi garantida nenhuma estrutura legal de apoio ou de orientação para eles, acabando por vitimizar os atingidos em todo esse processo. Observa-se que a forma de atuação dos Comitês foi um tanto curiosa, pois o seu propósito era o de intermediar junto ao Empreendedor os interesses dos atingidos, o que acabou se invertendo, pois os Comitês de Negociação tornaram-se defensores dos interesses do Empreendedor.

As relações da AMISTA com o movimento dos atingidos foram conturbadas, pois o MAB afirmou que a associação possuía interesses divergentes dos seus (STRADA, 2005, p. 53). Tal foi o grau de desentendimento, que o MAB se recusou a participar dos Comitês Municipais de Atingidos, por considerá-los ilegítimos. Com relação ao papel do MAB, Adilson Zeni declarou que:

[...] O MAB, em um determinado momento, notou que perdeu espaço, por que a AMISTA trabalhava com diálogo, não com agressão. Esse negócio de fazer movimento, de fechar estrada, a AMISTA não fazia isso. Então a gente percebeu que em determinado momento o MAB foi perdendo forças, de credibilidade naquela mensagem em que ele só mostrava o abismo. E distorcia um pouquinho os fatos. Mas eu reconheço que o MAB foi importante para algumas conquistas que os atingidos tiveram (Adilson Zeni, Liderança da AMISTA).

O Movimento de Atingidos por Barragem tem outra opinião a respeito da constituição da AMISTA. O representante do MAB destaca que a associação foi instituída exclusivamente com o intuito de se opor ao movimento social e forçar um discurso pró-barragem sobre as populações atingidas. Para a liderança do $\mathrm{MAB}$, o empreendedor precisava convencer os administradores municipais, pois são eles que fazem a opinião pública nos municípios, e criou-se, portanto, um 
mecanismo para cooptar os prefeitos, via AMISTA, definida pelo MAB como uma "comissão pró-barragem". A Associação foi criando o suporte necessário para que o Consórcio Foz do Chapecó entrasse na região, por meio da articulação de encontros, debates, no sentido de convencer a opinião pública.

Como se denota nas entrevistas, a AMISTA também agiu de acordo com os seus próprios interesses, defendendo os municípios. Contudo, a ideia de se opor ao MAB estava no mínimo equivocada, já que esta postura apenas permitiu o fortalecimento da empresa consorciada na região. Numa avaliação pósconstrução da hidrelétrica, Adilson Zeni, uma das lideranças da AMISTA, afirma que houve uma série de perdas para os municípios envolvidos na construção da hidrelétrica. Ele declarou que o município de Águas de Chapecó perdeu cerca de 61 famílias, pois, ao invés de permanecerem morando no local, por influência de imobiliárias procuraram terras na região de Concórdia, Lindóia e Ipumirim, sobretudo pela influência das agroindústrias, que atraem a força de trabalho jovem. E os jovens acabaram por incentivar os pais a venderem suas propriedades e mudar para as cidades, provocando o aumento do êxodo rural.

A Foz do Chapecó criou, também, para aqueles que não foram indenizados, projetos de "Geração de Renda", dos quais participam aproximadamente 500 famílias (observar o número de famílias). Foram investidos nesses projetos uma soma equivalente a cinco milhões de reais, pois já que estas pessoas não se enquadraram nos critérios de atingidos, a empresa "demonstra", desta forma, alguma preocupação com a subsistência delas. Exemplo notório desta ajuda foi um Projeto de Plantação de Tomates em Estufa, com o apoio técnico do Serviço Brasileiro de Apoio às Micro e Pequenas Empresas (SEBRAE), no município de Caxambu do Sul. Contudo, pelo visto, essas iniciativas de "Geração de Renda" não têm sido exitosas, como revela o Secretário dos Assuntos da Barragem de Caxambu do Sul, ao criticar os referidos empreedimentos de geração de renda:

Eles criaram ali, no Lajeado Bonito. Os filhos de atingidos que não ganharam carta de crédito fez uma associação pra plantar tomate. Daí eles deram uma área remanescente de dois, três ou quatro hectares pra eles trabalharem lá. No começo parecia bonito, mas agora está jogado, jogaram não sei quantos mil fora. Cinquenta ou sessenta mil reais, tudo jogado fora. Isso não vai funcionar - tudo no meio de gringo, eu disse pra eles, aqui a região é italiana, é um desconfiado do outro, que Deus o livre. Essa associação não funciona, se tivesse um líder, uma pessoa lá e pagasse um tanto pros cara, aí funciona. Agora, aonde todos mandam e ninguém obedece. [...] E daí eles põem na mídia, Caxambu do Sul, não sei o quê [...] é só fantasia (Lenoir Rolim de Moura, Secretário Municipal de Assuntos da Barragem de Caxambu do Sul).

Novos Cadernos NAEA • v. 16 n. 2 • p. 149-168 • dez. 2013 
As afirmações anteriores suscitam algumas dúvidas. Até que ponto uma Usina Hidrelétrica construída para o desenvolvimento regional compensa os eventuais impactos das comunidades, essencialmente agrícolas, envolvidas? E quando o Setor Público, maior fomentador do empreendimento, se alia a "interesses" contrários aos da população, não se está diante de uma crise de representatividade? Pode-se avançar nessa discussão afirmando que não haverá preocupação da sociedade civil da região, e nem do Poder Público, até o momento em que tais empreendimentos comprometam a própria base da economia regional, sobretudo de atividades que dependem essencialmente dos recursos hídricos, como a agricultura familiar. E será que não houve a preocupação de estudar qual seria o resultado da sinergia gerada pelo efeito de tantas Usinas sobrepostas? Entendemos que é importante o poder público, o mercado e a sociedade civil terem clareza sobre as consequências do Plano Nacional de Energia para a região, pois como alerta Denardin (2004):

A degradação dos recursos hídricos também pode inviabilizar a instalação de empresas na Região. As empresas que atuam no ramo agroindustrial, principalmente o de carnes, necessitam de água em quantidade e qualidade. [...] A poluição das águas pode afetar o desenvolvimento da pecuária, uma das principais atividades produtivas da Região. [...] Outra consequência da degradação dos recursos hídricos é a limitação do desenvolvimento de atividades produtivas voltadas para a exportação e a possível inviabilização da criação de uma marca regional. [...] Portanto, Oeste Catarinense é considerado um capital natural crítico e intervenções urgentes se fazem necessárias. [...] Assim, cabe a essa mesma sociedade, que se desenvolveu usufruindo desses capitais naturais, buscar em conjunto soluções que permitam um uso sustentável destes no longo prazo. (DENARDIN, 2004, p. 152-154, 195).

\section{CONSIDERAÇÕES FINAIS}

O Movimento de Atingidos por Barragens lutou não apenas pelas indenizações individuais, mas também no sentido de manter as comunidades unidas e impedir, de certo modo, o êxodo rural, pois a preferência do movimento entre as modalidades de indenização oferecidas pelo Empreendedor era o Reassentamento Rural Coletivo.

Por sua vez, a forma de atuação dos Comitês Municipais de Negociação, organizada pela AMISTA, foi um tanto curiosa, pois o seu objetivo era o de intermediar junto ao Empreendedor os interesses dos atingidos, o que acabou 
se invertendo, uma vez que os Comitês de Negociação tornaram-se defensores dos interesses do Empreendedor. A governança implantada via comitês foi fraca, pois foi imposta à visão unilateral do Empreendedor, que conseguiu monopolizar o processo a seu favor.

Todos perderam nesse processo, tanto os municípios atingidos, como as famílias atingidas. É ingenuidade crer que a atuação isolada de apenas um ator num processo tão complexo que envolve a construção de uma hidrelétrica, pode efetivamente se contrapor aos interesses do Empreendedor. Ao invés de se dividirem, todos deveriam ter se unido e buscado consensos, visando à mitigação dos impactos socioeconômicos e ambientais relacionados à construção da hidrelétrica, bem como uma indenização justa para os atingidos. Observa-se, ao longo do processo, um projeto bem arquitetado pelo Empreendedor, no sentido de fortalecer a AMISTA, via organização dos prefeitos dos municípios atingidos, com o intuito de enfraquecer o $\mathrm{MAB}$, que seria o ator social com maior estoque de capital social para dialogar com o Empreendedor.

Como lembra Ioris (2008, p. 66), não podemos subestimar as forças governamentais e de mercado na construção das hidrelétricas, "que produzem a destituição de recursos, a degradação ambiental e a redução das oportunidades de sobrevivência das comunidades locais".

\section{REFERÊNCIAS}

AGRA FILHO, Severino Soares. Os conflitos ambientais e os instrumentos da política nacional de meio ambiente. In: ZHOURI, Andréa e LASCHEFSKI, Klemens (org.). Desenvolvimento e conflitos ambientais. Belo Horizonte; Editora UFMG, 2010.

BARON, S. UHE Foz do Chapecó: estratégias dos agentes envolvidos e o desenvolvimento regional. Revista Brasileira de Planejamento e Desenvolvimento, v. 1., n. 1, p. 114-125, jul./dez. 2012.

BRASIL. Resolução No 26/2006 da SEDH da Presidência da República. Comissão Especial para acompanhar denúncias de violações de Direitos Humanos decorrentes da Implementação de Barragens. Disponível em: <www. cnh-srh.gov.br/delibera/resolucoes/r005.htm>. Acesso em: 21 ago. De 2000.

BERMANN, C. Impasses e controvérsias da hidreletricidade. Revista Estudos Avançados, v. 21, n. 59, 2007. 
CEPAL.Water Governance for Development and Sustainability. Santiago: CEPAL, 2006. (Serie Recursos Naturales e Infraestructura, n. 11).

DENARDIN, V. F. De capital natural a capital natural crítico: a aplicação da Matriz de Deliberação na gestão participativa dos recursos hídricos no Oeste Catarinense. 2004. 200f. Tese (Doutorado em Desenvolvimento, Agricultura e Sociedade) - Universidade Federal do Rio de Janeiro, Rio de Janeiro, 2004.

FOZ do Chapecó. Disponível em: http://www.fozdochapeco.com.br. Acesso em: 2 jul. 2010 .

GOHN, M.G.. O protagonismo da sociedade civil. Movimentos sociais, ONGs e redes solidárias. São Paulo: Cortez, 2005.

HASS, M.; ALDANA, M.; AMPOLINI, G. A legitimidade das audiências públicas dos processos de licenciamentos ambientais da Usina Hidrétrica Foz do Chapecó. In: ENCONTRO LATINO-AMERICANO CIÊNCIAS SOCIAIS E BARRAGENS, 3. 2010. Belém. Anais... Belém, 2010.

IORIS, A. A. R. Os limites políticos de uma reforma incompleta - a implementação da Lei dos Recursos Hídricos na Bacia do Paraíba do Sul. Revista Brasileira de Estudos Urbanos e Regionais, v. 10, n. 1, maio. 2008.

LOCATELLI, C. A. Comunicação e Barragens: o poder da comunicação das organizações e da mídia na implantação da Usina Hidrelétrica Foz do Chapecó (Brasil). 2011. Tese (Doutorado em Comunicação e Informação) - Universidade Federal do Rio Grande do Sul, Porto Alegre, 2011.

MACHADO, P.A.L. Direito Ambiental Brasileiro. São Paulo: Malheiros, 2000.

MARÇAL, C. Análise jurídica do procedimento do licenciamento ambiental. Jus Navigandi, Teresina, v. 9, n. 668, 4 maio. 2005. Disponível em: <http://jus2. uol.com.br/doutrina/texto.asp?id=6675>. Acesso em: 2 jun. 2010.

MME/EPE. Plano Nacional de Energia 2030. Rio de Janeiro, 2007.

MME/EPE. Plano Decenal de expansão da Energia 2011-2020. Rio de Janeiro, 2011.

POLI, O.L. Leituras em Movimentos Sociais. Chapecó: Grifos, 1999.

ROCHA, H. J. da. Carta aos atingidos: as negociações na bacia do Rio Uruguai. Disponível em: http://www.humanas.ufpr.br/evento/SociologiaPolitica/GTsONLINE/GT7\%20online/carta-atingidos-HumbertoRocha.pdf. Acesso em: 15 mar. 2010. 
SANTOS, S. C. dos; NACKE A. A implantação da UHE Machadinho num cenário privatizado: um caso para reflexão. In: REIS, M. J.; BLOEMER, N.M.S. (Orgs.). Hidrelétricas e populações locais. Florianópolis: Cidade Futura; UFSC, 2001.

STRADA, S. O processo de organização política dos moradores a serem atingidos pela Barragem de Foz do Chapecó - Goio-Ên. 2005. $76 f$. Monografia (Conclusão do curso Serviço Social) - Universidade Comunitária Regional de Chapecó, Chapecó, 2005.

VAINER, C. B.; ARAÚJO, F. G. B. de. Grandes projetos hidroelétricos e desenvolvimento regional. Rio de Janeiro: Cedi, 1992.

VAINER, C. B. Conceito de "Atingido": uma revisão do debate. In: ROTHMAN, F. D. (Org.). Vidas Alagadas - conflitos socioambientais, licenciamento e barragens. 1. ed. Viçosa: UFV, 2008.

VIGNAT'TI, M. Modificações territoriais induzidas pelas usinas hidrelétricas do Rio Uruguai no Oeste Catarinense. 2013. Tese (Doutorado em Geografia) - Centro de Filosofia e Ciências Humanas, Universidade Federal de Santa Catarina, Florianópolis, 2013.

ZHOURI, A.; OLIVEIRA, R. Desenvolvimento, conflitos sociais e violência no Brasil Rural: o caso das Usinas Hidrelétricas. Revista Ambiente \& Sociedade, Campinas, v. 10, n.2 p.119-135 jul.-dez. 2007. 